\title{
Entrevista: aspectos lingüísticos e pragmáticos
}

\author{
Mônica Santos de Souza \\ Universidade Federal de Ouro Preto
}

\begin{abstract}
:
The interview is today the most efficient resource to obtain and divulge information and facts about famous people: artists, politicians, scientists, sportsmen. In this text we will analyze linguistic and pragmatic factors that influence interview structure in some Brazilian magazines.
\end{abstract}




\section{INTRODUÇÃO}

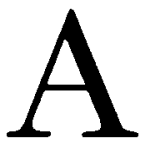

entrevista é um recurso para se obterem informações de vários tipos, empregado por profissionais de diversas áreas: médicos, juízes, assistentes sociais, sociólogos, psiquiatras, psicanalistas e comunicadores - jornalistas ou não. Quando veiculada pelos meios de comunicação, constitui uma das maneiras mais comuns pelas quais as pessoas tomam conhecimento dos fatos do dia-a-dia e se colocam a par de informações que dizem respeito à vida de personalidades do meio artístico, político e cultural do país. Como afirma MEDINA (1990), ela funciona como um mecanismo de distribuição democrática da informação.

Nosso objetivo neste trabalho é analisar entrevistas veiculadas pelos meios de comunicação, especificamente as publicadas pela imprensa escrita, estudando os fatores lingüísticos e pragmáticos responsáveis por sua estruturação. Acreditamos que a entrevista, enquanto forma particular de conversação, não constitui um fenômeno caótico, mas organizado e, por isso mesmo, passível de um estudo científico.

Trabalharemos, basicamente, com os pressupostos teóricos fornecidos pela "Lingüística do Texto" e pela "Análise da Conversação".

\section{ENTREVISTA}

\subsection{Conceituação}

A entrevista é uma forma de interação envolvendo um entrevistador, pessoa que faz perguntas e conduz a conversa, e o entrevistado, uma personalidade representativa dentro do contexto 
no qual a entrevista é produzida e para o qual é veiculada. Essa é, inclusive, uma de suas características: o enfoque de pessoas que estão em evidência no cenário nacional. Um dos fatores que a tornam uma forma especial de interação é, sem dúvida, o fato de ela não se restringir aos interlocutores, mas se destinar a espectadores (leitores ou ouvintes). Medina define a entrevista jornalística como "uma técnica de obtenção de informações que recorre ao particular; por isso se vale, na maioria das circunstâncias, da fonte individualizada e lhe dá crédito, sem preocupações científicas".

Ela é um tipo de interação que conjuga a espontaneidade que caracteriza uma conversação e o planejamento próprio de um discurso destinado a um determinado público e com um objetivo pré-estabelecido e, por isso mesmo, construído geralmente a partir de um questionário. É a associação destes dois elementos, a espontaneidade e o planejamento, que a torna uma forma de interação especialmente complexa. Ao conduzir seu interlocutor, o entrevistador deve estar atento aos virtuais tópicos oferecidos pela fala de seu entrevistado, estabelecendo assim um eixo de coerência ao longo da conversa, mas também deve procurar incluir, da forma mais natural possível, os temas previamente planejados, a fim de atender à curiosidade do seu público.

A edição de uma entrevista pode adquirir vários formatos. Nós nos preocuparemos especificamente com aquelas editadas no formato de diálogo explícito EU e TU ou, como se diz jornalisticamente, pergunta-e-resposta. Este formato caracteriza a entrevista conceitual (definida abaixo), já que os conceitos emitidos pela fonte de informação dispensam um narrador indireto. Este é o formato que mais se assemelha a um diálogo, composto de perguntas e respostas.

Encaramos a entrevista como uma espécie de diálogo assimétrico, ou seja, dirigido por um dos participantes, cujo conteúdo compõe um todo, com elementos que caracterizam um texto, entendido como "ocorrência lingüistica falada ou escrita, de qualquer extensão, dotada de unidade sociocomunicativa semântica e formal" 
(COSTA VAL, 1991). A entrevista seria, portanto, uma espécie de diálogo estruturado, composto de perguntas e respostas, que deve apresentar uma coerência, ou seja, uma continuidade de sentidos perceptível, não só entre a resposta e a pergunta formulada, mas também entre aquela e a próxima pergunta. Uma entrevista em que as perguntas ignorem completamente a fala anterior do entrevistado é tão incoerente quanto um texto cujas frases falem de coisas completamente desvinculadas. Afirma MEDINA:

Quando ocorre uma entrevista dirigida por um questionário estanque ou motivada por um entrevistador também fixado em suas idéias preestabelecidas (em geral, coincidentes com o questionário) e no autoritarismo impositivo, o resultado frustra o receptor. Até um leigo em técnicas de comunicação social percebe a ausência do diálogo. Freqüentemente, um adolescente ou uma criança comenta, diante de uma dessas entrevistas em televisão: 'O sujeito nem terminou o pensamento e o repórter já cortou...'.

\subsection{Classificação das entrevistas}

Edgard Morin (apud Medina) reflete sobre a entrevista na rádio e na televisão. Define a entrevista-extensiva, enquete com aplicação de questionários pré-elaborados e a entrevista intensiva, não-diretiva, aberta. Para ele, este último tipo proporcionaria um enriquecimento informativo já que nela o diálogo se desloca para o entrevistado; há liberação e desbloqueamento na situação inter-humana, permitindo que esta relação flua e que se atinja a auto-elucidação.

A partir desta classificação, Medina agrupa as entrevistas em duas tendências: a espetacularização e a compreensão (aprofundamento), sendo que cada uma apresenta subdivisões:

Subgêneros da espetacularização:

1. Perfil do pitoresco: retrato de pessoas de destaque.

2. Perfil do inusitado: descrição de traços excêntricos do entrevistado.

3. Perfil da condenação: entrevista ideologicamente marcada, que traça um perfil do entrevistado como culpado. 
Subgêneros da compreensão-aprofundamento:

1. Entrevista conceitual: consulta a especialistas para se obterem informações sobre determinados conceitos.

2. Entrevista enquete: utilização de várias fontes que irão depor sobre um tema.

3. Entrevista investigativa: uso de entrevistas para se embasarem investigações sobre fatos da vida pública.

4. Confrontação-polemização: discussão de temas polêmicos, envolvendo várias pessoas que se reunirão em mesasredondas, painéis, simpósios e seminários, cabendo ao entrevistador o papel de coordenador, mediador e portavoz de dúvidas do senso comum.

5. Perfil humanizado: entrevista com o objetivo de traçar um perfil humano do entrevistado, para se conhecer seu histórico de vida, seus conceitos, valores e comportamentos.

\section{FATORES LINGÜÍSTICOS E PRAGMÁTICOS}

Tentaremos definir como os fatores lingüísticos e pragmáticos são responsáveis pela unidade das entrevistas. Os dois grupos de fatores foram definidos por Costa Val.

\subsection{Fatores lingūísticos: coerência e coesāo}

2.1.1. coerência: a coerência é o fator responsável pela unidade de sentido de um texto. Resulta, portanto, de uma espécie de conexão conceitual entre os elementos que o compõem, determinando que este faça sentido, tanto para o produtor quanto para o leitor. Um discurso coerente caracteriza-se por uma continuidade, que se manifesta pela retomada de idéias e conceitos e pelo uso de mecanismos como a repetição ou elipse de itens. Outra característica de um discurso coerente é a progressão, ou seja, o acréscimo, num texto, de informações novas sobre elementos já mencionados, através de mecanismos como a distribuição dos tópicos e comentários 
associados, respectivamente, às infọmações dadas e novas. Estas informações devem estar articuladas, relacionadas no texto.

2.1.2. coesão: a coesão é a ligação entre os elementos superficiais do texto, a forma como eles se relacionam, o modo como frases ou partes delas se combinam para assegurar um desenvolvimento proposicional. (KOCH, 1991). Constitui um mecanismo léxico-gramatical responsável pela relação semântica entre os elementos de um texto. Os principais fatores de coesão são a referência, a substituição, a elipse, a conjunção e a coesão lexical. São elementos de referência os itens da língua que não podem ser interpretados semanticamente por si mesmos, mas remetem a outros itens do discurso necessários à sua interpretação. A referência pode ser exofórica, quando o item remete a algum elemento da situação, ou endofórica, quando o referente se acha expresso no próprio texto (anáfora e catáfora). A substituição é o uso de um item em lugar da repetição de outro já mencionado no texto. Quando há a substituição de um item lexical, sintagma ou oração, por zero, temos a elipse. A conjunção estabelece relações entre elementos ou orações do texto. Já a coesão lexical é efetuada por meio da reiteração ou repetição de um mesmo item lexical, e da colocação, que é o uso de termos pertencentes a um mesmo campo significativo.

\subsection{Fatores pragmáticos}

Os fatores pragmáticos dizem respeito às características específicas de cada ato comunicativo, que envolvem a relação entre os interlocutores, a situação de fala e o próprio tema do discurso. São eles: intencionalidade, aceitabilidade, situacionalidade, informatividade $\mathrm{e}$ intertextualidade. $\mathrm{A}$ intencionalidade consiste na construção, por parte do produtor, de um discurso coerente e coeso, que lhe permita alcançar determinados objetivos numa dada situação. A aceitabilidade diz respeito aos elementos responsáveis pela coerência, coesão, utilidade e relevância de um texto do ponto de vista do ouvinte ou leitor. Referem-se, basicamente, à necessidade de cooperação (no sentido de o produtor responder aos interesses 
de seu interlocutor), à qualidade (autenticidade), quantidade (informatividade) e relevância das informações, bem como à maneira como essas informações são apresentadas (precisão, clareza, ordenação, concisão). A situacionalidade é a propriedade que o texto tem de ser pertinente e relevante com relação ao contexto em que é produzido, ou seja, diz respeito à adequação do texto à situação de fala. A informatividade determina o interesse do recebedor pelo texto. Diz respeito à medida na qual as ocorrências de um texto são esperadas ou não, conhecidas ou não. Um discurso menos previsível é mais informativo, porque a sua recepção resulta mais interessante. A intertextualidade diz respeito à referência a outros textos. Alguns textos só fazem sentido quando entendidos em relação a outros, que funcionam como seu contexto. Isso ocorre na fala coloquial, em que se retomam conversas anteriores, e em pronunciamentos que requerem o conhecimento de discursos e notícias já divulgadas que são tomados como ponto de partida .

\section{DESCRIÇÃO DO MATERIAL ANALISADO}

Vamos tratar aqui de entrevistas veiculadas pela imprensa escrita pelas revistas Veja, ISTOE, Moda Moldes, Interview, Marie Claire, Ele Ela e Best View, no período de 91 a 94, excetuando-se a primeira entrevista (E1), que é de 88. Foram colecionadas 25 entrevistas que focalizam pessoas públicas que desempenham atividades variadas. São cantores, atores, políticos, empresários, esportistas e intelectuais, que expõem suas opiniões em espaços nobres nas revistas. Abaixo listamos as entrevistas estudadas.

3.1. Revistas de interesse geral (público femin. e masc.)

\subsubsection{Veja}

E1. Beatriz Segall - atriz.

E2. Antônio Ermírio de Moraes - empresário. 
E3. João Ubaldo Ribeiro - escritor.

E4. Bill Gates - empresário.

E5. Caetano Veloso - cantor.

E6. Lima Duarte - ator.

E7. Bussunda - humorista.

3.1.2. ISTOÉ

E8. Ivo Pitanguy - cirurgião plástico.

E9. Hebe Camargo - apresentadora.

E10. Romário - jogador de futebol.

E11. Rita Lee - cantora.

E12. Antônio Britto - político.

E13. Betinho - sociólogo.

E14. Renato Russo - cantor e compositor.

3.2. Revistas femininas

3.2.1. Moda Moldes

E15. Letícia Sabatella - atriz.

E16. Luíza Thomé - atriz.

\subsubsection{Marie Claire}

E17. Lucinha Araújo - mãe de Cazuza.

E18. Paula Lavigne - atriz.

3.2.3. Interview

E19. Maria Paula - apresentadora.

E20. Elza Soares - cantora.

E21. S1́lvia Pfeifer - modelo e atriz.

3.3. Revistas masculinas

\subsubsection{Best View}

E22- Ziraldo - cartunista.

E23- Márcia Romão - atriz. 


\subsubsection{Ele Ela}

E24- Betty Farias - atriz.

E25- Harold Robbins - escritor.

\section{FATORES LINGÜÍSTICOS E PRAGMÁTICOS NA ESTRUTURA DAS ENTREVISTAS}

Em linhas gerais, interessam-nos, ențe os fatores lingüísticos, a coerência, compreendida como unidade de sentido, e a cóesão, que se manifesta através de mecanismos como a referência, substituição, elipse, conjunção e coesão lexical. Entre os fatores pragmáticos, estudaremos a intencionalidade, a situacionalidade, a aceitabilidade, a informatividade e a intertextualidade.

\section{ANÁLISE DOS FATORES LINGÜÍSTICOS DA ESTRUTURAÇĀO DE ENTREVISTAS}

De acordo com KOCH \& TRAVAGLIA (1989), o termo coerência poderia ser usado em sentido geral para denotar que alguma forma de relação ou unidade no discurso pode ser estabelecida. A coerência seria uma propriedade não só do texto, mas de uma situação comunicativa entre usuários que têm modelos cognitivos comuns ou semelhantes, adquiridos em dada cultura.

Consideraremos tanto a noção de coerência quanto a de coesão aplicadas não só ao texto convencional, mas a qualquer situação comunicativa entre falantes. Para isso, será útil a noção de tópico.

\subsection{A noçāo de tópico}

ERIKSON (1982) propõe uma análise de uma situação de conversação através do estabelecimento da coesão a partir da manutenção do tópico. Os falantes, numa conversação, não apenas 
produziriam sentenças mas responderiam num momento àquilo que o interlocutor disse ou fez no momento anterior, preparando o que ele vai dizer ou fazer no momento seguinte. Para Erickson, não é de se estranhar que as pessoas envolvidas na conversação se deparem com os mesmos problemas práticos dos textos - os problemas de realizar e manter uma coordenação da produção da fala fluentemente recíproca e complementar - e empreguem alguns dos mesmos recursos que são empregados na produção de textos. Segundo ele, o caráter improvisador da conversação requer a pronta avaliação de tópicos como temas em torno dos quais os falantes poderão improvisar variações.

\subsection{Coerência}

Como vimos, a coerência é o fator responsável pela unidade de sentido de um texto, que resulta de uma espécie de conexão conceitual entre os elementos que o compõem e que se caracteriza, basicamente, pela continuidade e progressão.

Numa entrevista, a coerência se manifesta pela manutenção do tópico, que deverá ser desenvolvido por duas pessoas. Assim, o que uma pessoa fala deve ter relação com o que se disse anteriormente para que se estabeleça a coerência no diálogo. A falta de coerência nessas situações é um índice da falta de interação entre entrevistado e entrevistador. Quanto mais natural for a passagem de um tópico a outro, mais fluente e espontânea será a entrevista.

Pode haver um esquema de perguntas previamente elaborado, mas ele deve ser flexível a ponto de permitir que as perguntas sejam colocadas à medida que as falas dos entrevistados introduzam certos assuntos.

Notamos, na edição das entrevistas analisadas, uma tentativa de se organizar um texto coerente. As entrevistas se iniciam, normalmente, por uma espécie de introdução, em que se apresenta o entrevistado através de uma minibiografia e na qual se tecem alguns comentários sobre as atividades por ele desempenhadas. 
E2: Quem diria. O empresário Antonio Ermírio de Moraes, um dos homens mais ricos do Brasil, com uma fortuna de 1,5 bilhão de dólares, à frente de quase uma centena de empresas, que faturaram 3,2 bilhões de dólares no ano passado, um sujeito sério e sisudo, virou um artista.(...) Pois é: o Antonio Ermírio de Moraes acaba de escrever uma peça.(...)

O fato de Antonio Ermírio de Moraes ter escrito uma peça, citado na introdução, é o tema da primeira pergunta a ele dirigida, o que revela um cuidado em se criar um texto estruturado, com uma continuidade:

Veja: Que peça é essa que o senhor acabou de escrever?

Essa continuidade, em termos de conteúdo, se evidencia também na retomada de idéias ou conceitos mencionados anteriormente pelos entrevistados. É o que se nota com relação às afirmações de Renato Russo:

E16: Renato Russo:(...) Escolhi fazer um disco só com canções em inglês para não confundir com o trabalho do Legião. São canções de amor, eu cantando para um outro cara.

IstoÉ: Quando e como foi que o sr. resolveu assumir publicamente sua homossexualidade?

Ao mesmo tempo em que há uma retomada de conceitos há um acréscimo de informações que caracterizam a progressão. Esse acréscimo se dá através de perguntas que procuram explorar um aspecto diferente com relação a determinada idéia ou conceito mencionado anteriormente. Os casos mais evidentes são aqueles em que um conceito é retomado como tópico na pergunta seguinte. Como exemplo temos:

E9: Bussunda:(...) Eu não deixo a minha filha ver uma coisa dessas de jeito nenhum. Em matéria de chatice, a Bia Bedran é o Oswaldo Montenegro de saias.

Veja: Quem são hoje os outros campeões da chatice no país? 
E2: A. Ermírio: Aqui na minha empresa se trabalha $90 \%$ do tempo e se conversa $10 \%$. Na política é o inverso. Aprendi mais: que ciúme de homem é uma desgraça. É pior do que ciúme de mulher.

Veja: O que é ciúme de homem?

\subsection{Coesão}

Um mecanismo que contribui para que se estabeleça a coerência é a coesão. A coesão se manifesta, como vimos acima, de várias maneiras. Uma delas é a conjunção, isto é, o uso de conectores para se estabelecerem ligações entre o que foi e o que ainda será dito. Como exemplo, temos o uso de conjunções como e, que indicam uma conclusão ou acréscimo a partir do depoimento anterior. Notamos que estes conectores são bastante comuns ao se introduzir uma questão, relacionando-a à fala anterior. É o que verificamos em:

E6: Gates: Não. Foi o The Wall Street Journal quem fez a conta, sempre com base no valor das ações da Microsoft. Eu li a notícia no Journal.

Veja: E o que the veio à cabeça?

Outro mecanismo para se estabelecer a coesão é a referência, que compreende, basicamente, a anáfora e a dêixis, que correspondem, respectivamente, ao uso dos pronomes ele e você, em E7:

E7: Caetano: Eu queria que o presidente fosse o Brizola.

Veja: Ele seria um presidente melhor do que Collor?

Caetano: (...) E preciso fazer uma campanha sobre o sinal vermelho.

Veja: Você faria essa campanha?

A coesão lexical, obtida por meio da reiteração e da colocação, também aparece nas entrevistas analisadas, estabelecendo uma conexão entre a resposta do entrevistado e a pergunta que a ela se segue. 
E13: Romário: (...) Mas depois que você atinge um nível como ele atingiu, um dos maiores nomes do futebol mundial de todos os tempos, se deixar passar por isto...aí é um problema de inteligência.

IstoÉ: Falta inteligência?

E11 : Hebe: É, posso dizer que o Jânio Quadros telefonava para minha casa, queria se encontrar comigo. Eu nunca fui e nos últimos tempos ele me encarava com respeito. Diziam que ele queria todas e como era presidente...

IstoÉ: Essa investida telefônica era feita de Brasília?

E14: Antônio Britto: (...) O governador Quércia é evidentemente um nome em exame, mas também é verdade que ele enfrenta grandes resistências. Os próximos dias vão dizer se ele consegue superá-las, tornando-se um nome de consenso, ou se teremos de partir para outra alternativa.

IstoÉ: Há demanda eleitoral para esse projeto de articulação das forças de centro?

Também a elipse ou omissão de um item lexical, sintagma ou oração, aparece como elemento de coesão, como em:

E14: Antônio Britto:(...) No momento oportuno creio que esse quadro que aí está vai sofrer grandes mudanças.

IstoÉ: Quais?

\section{ANÁLISE DE FATORES PRAGMÁTICOS DA TEXTUALIDADE DAS ENTREVISTAS}

Os fatores pragmáticos expostos acima determinam o formato dos textos. É o que Costa Val quer dizer quando afirma que a conjugação desses fatores tem como conseqüência a existência de diversos tipos de discurso. Afirma ela: A praxe acaba por estabelecer que, numa dada circunstância, tendo-se em mente determinada intenção ilocucional, deve-se compor o texto dessa ou daquela maneira. Assim, há convenções que regem o funcionamento da linguagem na interação social e que determinam qual o tipo particular de discurso adequado a cada ato comunicativo. 
Quanto à intencionalidade, nota-se que as entrevistas visam a um certo objetivo, que pode ser simplesmente desenvolver uma conversa sobre temas particulares e banais, assemelhando-se a mexericos, traçar o perfil de uma personalidade, obter informações sobre problemas relevantes ou temas polêmicos ou levar o leitor a compartilhar de um ponto de vista. O objetivo de uma entrevista $\mathrm{e}$ seu nível de informatividade estão diretamente relacionados ao público ao qual ela se destina.

As entrevistas também devem dispor as informações de uma maneira precisa, clara, ordenada e concisa. Devem se adequar à situação em que são produzidas, assumindo certo formato, principalmente em função da figura do entrevistado.

A intertextualidade se manifesta através dos conhecimentos que o entrevistador demonstra ter de textos, pronunciamentos ou conversas envolvendo a figura entrevistada ou os temas abordados.

\subsection{O público-alvo}

Um dos elementos que caracterizam a entrevista como um tipo especial de conversação é o fato de ela se destinar a certo público.

BERLO (1985) define a importância do público em toda situação de comunicação humana. Para ele, uma das dimensões de qualquer análise de propósito comunicativo é a descoberta do receptor a quem se destinou a mensagem. Para ele, "ao produzir, receber ou criticar qualquer comunicação, deve-se formular a determinação do objetivo do comunicador nos seguintes termos: Como o comunicador pretendia atingir quem? Objetivo e audiência são inseparáveis. Todo comportamento de comunicação tem como objetivo a obtenção de uma reação específica de uma pessoa especifica (ou grupo de pessoas)". E continua: "Falamos sobre objetivo principalmente do ponto de vista da pessoa que inicia a comunicação, e há pelo menos dois conjuntos de respostas desejadas: $1^{\circ}$, a resposta que interessa a pessoa que produz a mensagem, e $2^{\mathbf{o}}$, a que interessa a quem recebe a mensagem. Os 
leitores têm objetivos, tanto quanto os e.scritores; as plateias os tem, tanto quanto os artistas."

O entrevistador é um representante de um grupo. Deve, então, tentar satisfazer não só a sua curiosidade, mas também a de seu público. A necessidade de satisfazer a demanda social, de responder aquilo que o público quer saber, deve falar mais alto do que suas preferências pessoais.

Uma entrevista interessante é a que consegue conciliar vários elementos, considerando, especialmente, a figura do entrevistado, os objetivos que se pretende alcançar e o nível de informatividade almejado. Estão envolvidos, então, elementos relacionados à figura do entrevistado, seu ramo de trabalho, classe social e nível cultural. Há ainda as variáveis relacionadas ao público a que ela se destina, determinadlas pelo tipo de publicação. Isto significa que um mesmo entrevistado responderá a perguntas diferentes, em diferentes publicações.

A avaliação de uma entrevista deve ser feita, portanto, em termos de sua eficiência, ou seja, da maneira pela qual ela atingiu seus objetivos, que são, em grande parte, determinados pelo público a que se destina.

\subsection{Definição do público-alvo}

Para definição do público-alvo, foram entrevistados informantes de idade, classe social e nível de escolaridade variados. $\mathrm{Na}$ oportunidade, investigamos a preferência dessas pessoas em termos de leitura - especificamente de periódicos - e a razão dessa preferência. Também procuramos saber o que essas pessoas buscavam na seção de entrevistas das revistas lidas.

É difícil definir em termos de faixa etária e escolaridade o público-alvo das revistas analisadas, que dividimos em três grupos: G1: revistas de interesse geral, G2: revistas femininas e G3: revistas masculinas. A avaliação que fizemos mostra que há uma diferença em termos daquilo que os leitores esperam de uma entrevista. $O$ 
grupo que lê as revistas do G1 se caracteriza por ser um público que lê com mais freqüência e que procura numa entrevista informações que vão além de detalhes e curiosidades sobre a vida particular do entrevistado. Os leitores de G2 e G3 são leitores eventuais, que lêem revistas com objetivos bem específicos, normalmente obter informações sobre uma determinada personalidade. Veja como a revista Best View define seu público:

Uma revista para o Homem moderno. Que gosta de mulher bonita, naturalmente... Para ver e, sempre que possível, consumir. Um Homem inteligente, que aprecia o papo de outros Homens também inteligentes, em entrevistas que se propõem a revelar a face oculta de gente famosa. Um Homem que é vidrado num bom carro - nacional ou importado - e em boas bebidas, idem. Que sabe se vestir, é claro, mas que também gosta de estar por dentro das novidades que, às vezes não tem tempo de olhar nas vitrines. Aquele que pretende que uma revista fale de lazer, com dicas sobre livros, filmes, fitas, discos, exposições e um turismo diferente - no Brasil ou em outras plagas. Que tenha contos e até horóscopo - de preferência erótico. E boas piadas, rapidinhas, picantes, mas inteligentes. Porque bom gosto, para ele, é fundamental...

Essa visão do Homem (com $\mathrm{H}$ ) como um ser inteligente e da mulher como objeto que pode ser "consumido", transparece nas entrevistas publicadas tanto nesta quanto na outra revista masculina.

\subsection{Análise de fatores pragmáticos na estrutura das entrevistas}

Notamos que a temática das entrevistas é determinada, em grande parte, pelo público ao qual se destinam. Em termos da intencionalidade, nota-se que o objetivo pode variar da simples exposição de assuntos corriqueiros relacionados à figura do entrevistado, à veiculação de informações para convencer o leitor acerca de uma opinião. Muitas perguntas tentam induzir o leitor a compartilhar de um ponto de vista ou procuram levantar pontos polêmicos, se considerarmos que muitas não são apenas perguntas mas trazem, explícitas ou implícitas, opiniões contestáveis: 
E11: Istoḱ: Quanto à nova safra literária de Cláudio Humberto e essas últimas baixarias de Pedro Collor e companhia. Isso chegou a impressioná-la ou, a partir de um determinado momento, nada mais é surpresa?

E12: Veja: Nem sempre é fácil ver teses nítidas em Lula. Ele era parlamentarista e o PT ficou no presidencialismo. No último encontro do PT, seus aliados acabaram derrotados pelos grupos de esquerda. Também é pouco nítida sua visão de Estado...

A inclusão de comentários como os mencionados acima aumenta o grau de informatividade das entrevistas e é uma característica de entrevistas que pertencem ao subgênero da compreensão-aprofundamento.

Vamos tentar agrupar as entrevistas observando a classificação proposta por Medina.

\subsubsection{Revistas femininas}

Nas revistas femininas encontramos exemplos da espetacularização, o que evidencia um preconceito quanto aos interesses da mulher. As entrevistas se restringem à discussão de temas pitorescos, particulares ou a um perfil do entrevistado. Como exemplo, temos as entrevistas de Elza Soares e Maria Paula a Interview:

E3: - Você falava com ele (João Gilberto) pessoalmente ou por telefone?

- Você namorou o João?

- E cantor você namorou?

- Jogador de futebol, só o Mané também?

E22: - Mas você ia à escola punk mesmo?

- Você anda com o Renato Russo?

- Com o Herbert Vianna?

Na revista Moda Moldes há um interesse por estética e moda, devido, naturalmente, à especificidade da revista, como mostram as perguntas dirigidas à atriz Luíza Thomé: 
E19: - Em pleno verão você segue algum ritual para cuidar do corpo?

- O que é moda pra você?

Em Marie Clair há uma preocupação em se traçar o perfil do entrevistado que, no entanto, não vai além do particular, como na entrevista de Paula Lavigne:

E21: - Você foi precoce, com 13 anos já tinha vida noturna, ia a festas, bares...

- Bebidas, drogas, sexo, como você vivia isso tudo?

- Para quem você faz confidências, se abre mesmo?

- Você fez ou faz análise?

- Você se achava feia?

Em vários momentos se faz referência à relação de Paula e Caetano Veloso. É como se a atriz estivesse sendo utilizada como fonte de informações da vida de um ídolo das leitoras.

E21: - Você era muito menina quando começou a transar com o Caetano?

- Parece, então, que foi ele que te seduziu?

- Em casa, quem é que administra o dinheiro?

Comportamento semelhante ocorre na entrevista de Lucinha Araújo. Das 48 perguntas feitas, 28 dizem respeito diretamente a Cazuza. Porém, neste caso, há pelo menos uma tentativa de se ir além da simples biografia do cantor através do depoimento da mãe, já que são introduzidas algumas perguntas relacionadas à questão da Aids:

E20: - Como nasceu a Sociedade Viva Cazuza?

- Como você entende a praga da Aids descendo sobre a humanidade?

Notam-se certos comentários que tentam dar um tom emotivo ou comovente à entrevista: 
E20: - Você está bonita, há brilho nos seus olhos.

- Você se sente culpada de continuar viva?

- Você se deixou massacrar por culpa?

- Você ainda pergunta "onde eu errei"?

\subsubsection{Revistas masculinas}

Nas entrevistas publicadas em revistas masculinas há a presença tanto da espetacularização quanto da compreensão. $A^{\prime}$ especulação sobre a vida particular, com a valorização de detalhes da vida sexual do entrevistado, é comum quando se entrevistam mulheres. Parece que o único atrativo em uma mulher para os homens é o aspecto físico e a vida particular. Como exemplos, temos as entrevistas de Betty Faria e Márcia Romão às revistas Ele Ela e Best View, respectivamente.

E29: - Esse solteira quer dizer sem nenhum namorado, ninguém especial no momento?

- Mas se casaria de novo?

- Você fez muito tempo de análise?

- Mudando de assunto, é verdade que você namorou o ator Maurício Branco?

- Betty, você é uma das poucas pessoas famosas que assumiu que já teve relações homossexuais, com mulheres...

- Foi curiosidade ou uma vontade momentânea? Porque você também sempre disse que gosta é de homens.

E28: - Márcia você tem namorado? Fale um pouco sobre ele.

- Qual a parte do corpo de seu namorado que mais lhe atrai?

- E sexualmente, qual a parte do corpo que mais lhe agrada?

- Pra você tamanho é documento?

- Com quantos anos você transou pela primeira vez?

- Você já teve experiências sexuais com mulheres?

- Conte um sonho erótico para a gente.

- Qual o local mais estranho em que você fez amor?

- O que é ser bom de cama para você?

- Qual a importância do beijo numa relação sexual?

- E pudores sexuais, você tem? 
Quando os entrevistados são homens, as perguntas se direcionam para temas mais complexos, sendo que a vida particular do entrevistado é mencionada apenas quando é tomada como ponto de partida para a compreensão de sua vida profissional, seus conceitos e valores. Observe algumas perguntas extraídas das entrevistas de Harold Robbins e Ziraldo, e a impressionante diferença de temática e conseqüente elevação do grau de informa-tividade, com relação às anteriores. Nestes casos ressalta-se não a vida particular, mas a vida profisssional do entrevistado, traçando-se o perfil de homens inteligentes e realizados.

E30:- Como o senhor reage às críticas em relação aos seus livros, que alguns consideram comerciais e superficiais, feitos exclusivamente para vender muito?

- Qual é a fórmula do sucesso?

- O que lhe dá mais orgulho: os livros que escreveu ou o dinheiro que ganhou com eles?

- Seus livros têm sempre quatro temas certos: sexo, traição, poder e ambição. Qual é o motivo para essa insistência?

E27: - Numa entrevista antiga, você se define como grafista, inspirado no artista gráfico Folon que cunhou esse termo. Hoje em dia, depois de ter desenvolvido uma carreira tão diversificada, como é que você se definiria?

- O interessante é que apesar de ter recebido uma forte doutrinação pró-americanista em sua escola secundária dirigida por pastores norte-anmericanos, você sempre foi imbuído de determinação de fazer um humor bem brasileiro, bem nacionalista, que tem na Turma do Pererê seu paradigma máximo.

- Como foi que o Pasquim começou?

O grau de informatividade mais elevado manifesta-se por comentários relevantes, que incluem a intertextualidade.

\subsubsection{Revistas de interesse geral}

As revistas de interesse geral atendem tanto ao público feminino quanto ao masculino. Nelas predominam entrevistas que 
se caracterizam por pertencer ao subgênero da compreensão, com exemplos de entrevistas conceituais (consulta a especialistas sobre determinados conceitos), das chamadas entrevistas-diálogo, em que se tenta trazer à tona uma verdade que pode dizer respeito à pessoa do entrevistado ou a um problema e do perfil humanizado, em que se procuram compreender conceitos, valores e comportamentos, além do histórico de vida do entrevistado. A temática se deve, nesse caso, à necessidade de se satisfazerem as curiosidades de um público mais exigente. Uma entrevista com uma atriz que interpreta uma personagem polêmica numa telenovela seria um ótimo pretexto para se conhecerem apenas os próximos capítulos da novela. No entanto, numa entrevista em que o público exige um nível de informatividade maior, o comportamento da personagem interpretada pela atriz em questão funciona apenas como um pretexto para se comentarem assuntos polêmicos. É o que se observa na entrevista de Beatriz Segall, que interpretava na época a personagem Odete Reutman.

E1: - Em quem a Odete Reutman teria votado para prefeito nas últimas eleições?

- Você acredita que a corrupção e o oportunismo que Vale Tudo mostra são a tônica do país atualmente?

- Você trocaria o Brasil por Paris, como seu personagem faria?

\section{CONCLUSĀO}

Tentamos aqui estudar alguns elementos que compõem a estrutura da entrevista, considerando tanto fatores lingüísticos quanto os fatores pragmáticos que influem na sua elaboração. Notamos que, em termos lingüísticos, a entrevista se caracteriza por uma coerência e por uma coesão, sendo neste caso relevante a determinação do tópico. Quanto aos fatores pragmáticos, notamos que as entrevistas se caracterizam por manifestar intencionalidade, aceitabilidade, situacionalidade, intertextualidade e informatividade, sendo esses fatores determinados em grande parte pelo público ao qual a entrevista se destina. 
Este trabalho integra uma pesquisa maior que pretende compreender melhor essa forma de interação tão complexa e importante nos nossos dias que é a entrevista.

\section{REFERÊNCIAS BIBLIOGRÁFICAS}

BERLO, D.K. O processo da comunicação: introdução à teoria e à prática. 5. ed., São Paulo: Martins Fontes, 1985.

COSTA VAL. M.G. Redação e Textualidade. São Paulo: Martins Fontes, 1991.

ERICKSON, F. Money Tree, Lasagna Bush, Salt and Pepper: Social Construction of Topical Cobesion in a Conversation among Italian-Americans. George Town University Press: Washington, 1982.

GERALDI, J.W. Portos de Passagem. São Paulo: Martins Fontes, 1993.

KOCH, I. V. \& TRAVAGLIA, L.C. Texto e Coerência: São Paulo: Cortez, 1989.

KOCH, I.V. Coesão Textual. São Paulo: Contexto, 1991.

MARCUSCHI, L.A. Análise da Conversação. São Paulo: Ática, 1986.

MEDINA, C.A. Entrevista. O diálogo possivel. 2. ed. São Paulo: Ática, 1990.

Revistas analisadas:

Veja, n. 1209, 20 nov. 91 .

Veja, n. 1228, 01 abr. 92.

Veja, n. 1309, 13 out. 93.

Veja, n. 1316, 01 dez 93.

Veja, n. 1329, 02 mar 94.

Veja, n. 1327,16 fev. 94.

ISTOÉ, n. 1225, 07 abr. 93.

ISTOÉ, n. 1224, 14 abr. 93.

ISTOE, n. 1227, 28 abr. 93.

ISTOE, n. 1248, 01 set. 93.

ISTOÉ, n. 1223, 31 mar. 93.

ISTOÉ, n. 1270, 02 fev. 94.

ISTOÉ, n. 1277, 27 abr. 94.

Moda Moldes, n. 67, jan. 92

Marie Claire, n. 44 , nov. 94

Interview, n. 178, out. 94.

Interview n. 176, ago. 94.

Ele Ela, nov. 94.

Such View, n. 01, nov. 94. 